\title{
The Hormonal Regulation of Pyloric Sphincter Function
}

\author{
Robert S. Fisher, William Lipshutz, and Sidney Cohen \\ From the Gastro-Intestinal Section, Department of Medicine, Hospital of the \\ University of Pennsylvania and Veterans Administration Hospital \\ Philadelphia, Pennsylvania 19104
}

A в S T RAC T The purpose of this study was to evaluate the hormonal control of pyloric sphincter function. Studies were performed on both pyloric circular muscle, in vitro, and the human pylorus, in vivo. Full dose-response curves to gastrin I, cholecystokinin, and secretin were constructed for the pyloric muscle of the opossum studied at its length of optimal tension development, Lo. Both cholecystokinin and secretin were potent agonists on the muscle but gastrin I gave no increase in muscle tension. The combination of cholecystokinin and secretin was additive at submaximal concentrations but potentiation of the maximal responses was not observed. Gastrin I produced a surmountable, competitive-like antagonism to the effect of cholecystokinin on the pyloric muscle. The octapeptide of cholecystokinin was a more potent agonist than the whole molecule of cholecystokinin on the pyloric muscle. In man, the pyloric pressure rose significantly during intravenous infusion of either cholecystokinin or secretin. The combination of maximal doses of both hormones did not show signficant potentiation. Gastrin I did not significantly increase pyloric pressure but did antagonize the pyloric response to duodenal acidification. These studies suggest that: (a) Both secretin and cholecystokinin augment pyloric sphincter pressure while gastrin $I$ is an antagonist inhibiting their effects. (b) The hormonal responses of pyloric sphincter circular muscle, in vitro, can be correlated with human sphincter function, in vivo.

\section{INTRODUCTION}

Intraluminal manometry employing open-tipped infused catheters has recently been utilized to show that the human pylorus is characterized by a zone of elevated pressure which relaxes with antral peristalsis, contracts in response to intraduodenal stimulation, and prevents the

Dr. Fisher's present address is Temple University Health Sciences Center, Philadelphia, Pennsylvania 19140.

Received for publication 14 August 1972 and in revised form 2 January 1973. retrograde movement of duodenal contents into the stomach (1). Similar properties suggesting a sphincteric function have been recorded at the canine pylorus $(2,3)$. The mechanism by which the human pylorus contracts in response to the intraduodenal instillation of amino acids, olive oil, and $\mathrm{HCl}$ is not known. It has been presumed to be hormonal because the substances which were instilled into the duodenum are known to release both secretin and cholecystokinin (4-11). In addition, a precedent for hormonal regulation of other gastrointestinal sphincters has been established (12-16). The purpose of this study is: (a) to utilize pyloric circular muscle, in vitro, to characterize the interaction of the gastrointestinal hormones on the pyloric sphincter; and (b) to relate these observations on pyloric muscle, in vitro, to studies carried out in man, in vivo.

\section{METHODS}

In vitro cxperiments. Studies were performed on 12 adult opossums of both sexes, weighing $2.6-5.2 \mathrm{~kg}$. The methods outlined here have been described previously in detail $(17,18)$. All animals were killed by intravenous pentobarbital. The entire stomach and duodenum were mobilized and freed from surrounding tissues. The distal duodenum was ligated and the upper gastrointestinal tract from esophagus to distal duodenum was excised and washed in Krebs-Ringer solution (composition in millimoles per liter: $\mathrm{Na}^{+}, 138.6 ; \mathrm{K}^{+}, 4.6 ; \mathrm{Ca}^{++}, 2.5 ; \mathrm{Mg}^{++}, 2.1 ; \mathrm{Cl}^{-}, 126.2$; $\mathrm{HCO}_{3}{ }^{-}, 21.9 ; \mathrm{PO}_{4}, 1.2$; glucose, 49.6) at $37-38^{\circ} \mathrm{C}$. The tissue was then transferred to an organ bath of KrebsRinger solution, bubbled with $95 \% \quad \mathrm{O}_{2}$ and $5 \% \quad \mathrm{CO}_{2}$, and maintained at $37-38^{\circ} \mathrm{C}$. The pylorus was identified as a distinct, prominent anatomic ring at the junction of the duodenum and antrum. The pyloric ring was separated from the antrum proximally and from the duodenum distally. The mucosa from each region was removed to the level of the submucosa. The antral circular muscle strips were taken $2 \mathrm{~cm}$ proximal to the pylorus. Each anatomic region was identified histologically by its lining epithelium. The antrum and pylorus were lined by columnar epithelium with gastric glands. No Brunner's glands or intestinal villi were present in pyloric sections.

Circular smooth muscle strips, $0.5 \mathrm{~cm}$ wide and $1.0 \mathrm{~cm}$ long, were cut from each anatomic region. Each muscle was mounted in a $20 \mathrm{ml}$ bath of Krebs-Ringer solution, 


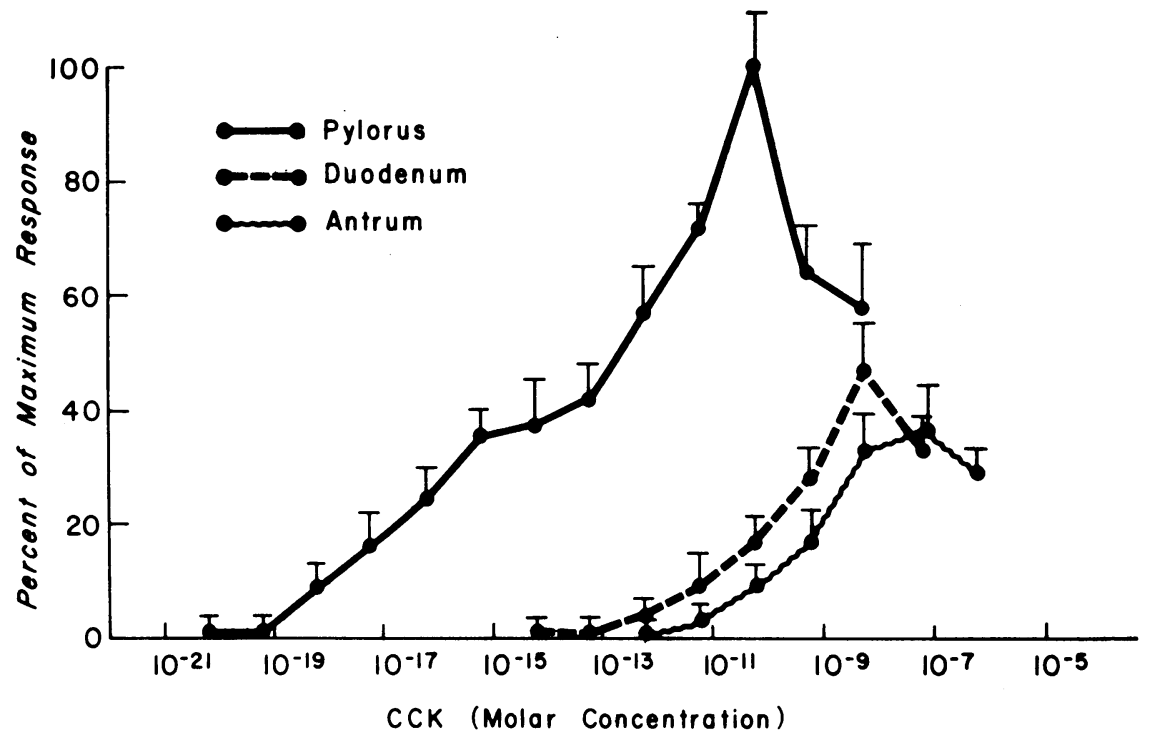

Figure 1 Cholecystokinin (CCK) dose-response curves at Lo for pyloric antral and duodenal circular muscle. Active tension is expressed as a percent of maximum response of pyloric muscle. Each point represents mean+SE for 12 separate experiments. Pyloric muscle responded at a lower threshold dose and attained a greater maximum active tension than muscle from adjacent areas.

bubbled with $95 \% \quad \mathrm{O}_{2}$ and $5 \% \quad \mathrm{CO}_{2}$, and kept at $37-38^{\circ} \mathrm{C}$. All strips were arranged to record the isometric tension of the circular smooth muscle. One end of the muscle was attached to an inflexible wire which was hooked to an external force transducer (Grass FT-03C, Grass Instrument Co., Quincy, Mass.). The other end was attached to a metal rod which could be raised and lowered by adjustment of a screw micrometer. The isometric force from each transducer was graphed on a Beckman curvilinear inkwriting recorder (Beckman Instruments, Inc., Fullerton, Calif.).

After a $30 \mathrm{~min}$ equilibration period, length-tension curves were constructed as previously described $(17,18)$. Each muscle at graded increases in length, was stimulated with $10^{-4} \mathrm{M}$ acetylcholine. The length of maximum active tension development, Lo, ${ }^{1}$ was thus obtained for each muscle studied. All muscles were then set at their respective Lo for the remainder of the experiment.

Dose-response curves were constructed on each muscle strip, at Lo. Each hormone and paired combination was given in randomized order. The response of each muscle was used as its own control. Cholecystokinin, mol wt 3950, secretin, mol wt 3055 (GIH Research Unit, Karolinska Institute, Stockholm, Sweden), and gastrin I, mol wt. 2098 (amino acid residue 2-17; Imperial Chemical Industries, Ltd., Alderley Park, Cheshire, England), were solubilized with Krebs-Ringer solution, and $1 \mathrm{ml}$ volumes were added to a $20 \mathrm{ml}$ bath to obtain the final molar concentration as noted. The molar concentration of secretin was calculated using $3.4 \mathrm{U}$ of secretin being equal to $1 \mu \mathrm{g}$ (19). The molar concentration of cholecystokinin was calculated using the stated quantity of $0.03 \mathrm{mg}$ of active peptide per $75 \mathrm{U}$ vial. Octapeptide of cholecystokinin, mol wt 1142 (The Squibb Institute for Medical Research, Princeton, N. J.), was evaluated in a similar manner. The dose-response curves

${ }^{1}$ Abbreviation used in this paper: Lo, length of maximum active tension,development. were constructed using individual doses given in random order. No cumulative doses were given. The response to each dose of a hormone was recorded over a $10 \mathrm{~min}$ period. The maximum tension recorded at each dose was used to construct the dose-response curves. The peak spontaneous contractions of each muscle during control periods were quantified and subtracted from the peak tension recorded at each dose. Stimulation of these muscles produced an increase in the amplitude of the spontaneous contractions with low concentrations of the hormone. At higher concentrations, the entire base-line pressure often became elevated. The muscle response to each hormone began promptly and was dissipated within $5 \mathrm{~min}$. In the experiments where hormone combinations were utilized, studies were performed both by adding one hormone before the other and by simultaneous addition of the two hormones into the bath. At least 15 min were allowed between each dose combination. All muscles were lightly blotted and weighed at the termination of the experiment. All active tensions have been corrected for muscle weight.

In vivo studies. 10 normal volunteer subjects, 8 males and 2 females, age $21-54$ yr (mean, 29) were studied. The subjects had no history of abdominal surgery and no symptoms of gastrointestinal disease. Informed consent was obtained from all volunteers.

The tube assembly and recording apparatus utilized in these studies has been previously described (1). Five polyvinyl catheters were joined together into a single unit with an outside diameter of $5.4 \mathrm{~mm}$. Intraluminal pressures were measured using three water-filled catheters, each infused with distilled water at $1.1 \mathrm{ml} / \mathrm{min}$, with their side orifices $1.2 \mathrm{~mm}$ in diameter, spaced at $1 \mathrm{~cm}$ intervals. The pyloric sphincter pressure was taken as the mean respiratory value obtained from the maximum zone of tonic pressure elevation. Phasic contractions were not quantified. The pressures recorded from the three recording orifices were meaned for each pull-through. All pressures were expressed using intra- 


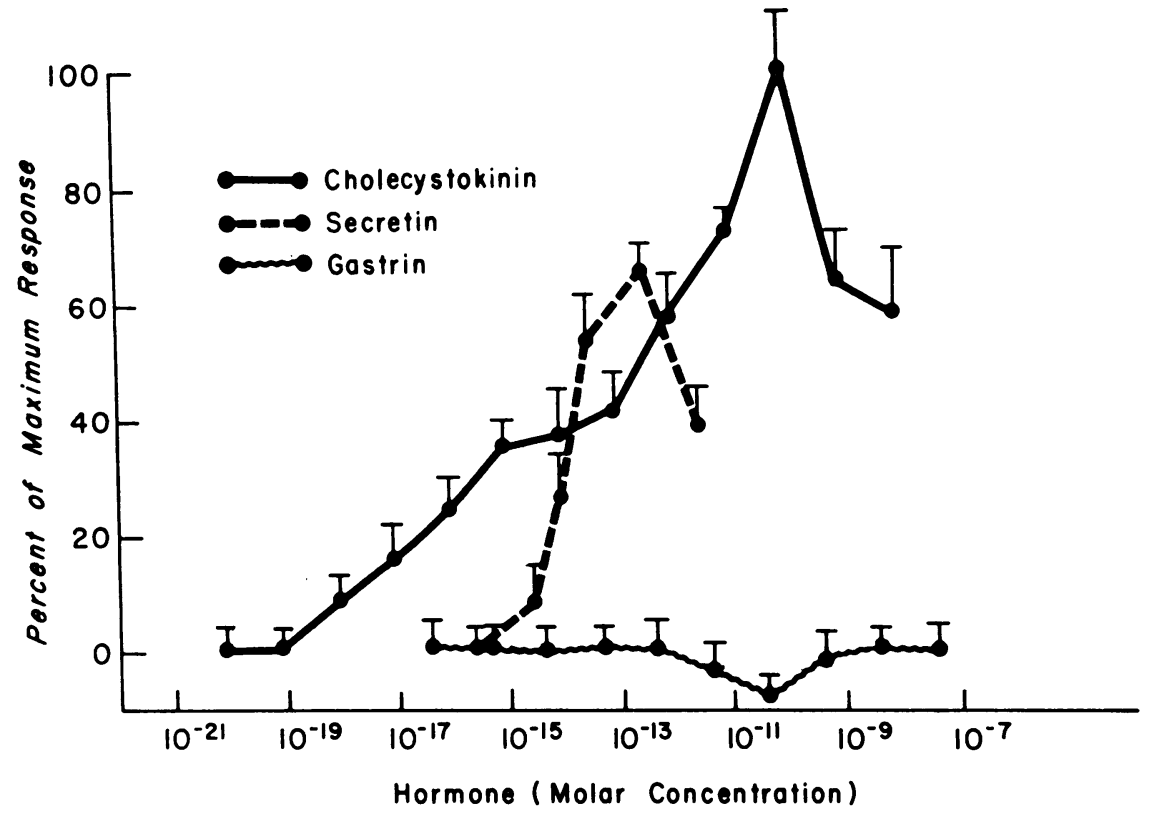

FiguRE 2 Cholecystokinin, gastrin I, and secretin dose-response curves at Lo for pyloric circular muscle. Active tension is expressed as a percent of maximum response to cholecystokinin. Each point represents mean+SE for 12 separate experiments. Both cholecystokinin and secretin increased the active tension. Pyloric muscle was inhibited by gastrin, but this response was not statistically significant $(P>0.05)$.

abdominal (intragastric) pressure as a zero reference. A fourth catheter was employed to measure forearm skin to mucosa electrical potential difference (PD) using $\mathrm{KCl}$ bridges. The $\mathrm{PD}$ recording orifice was at the same level as the middle pressure detector. The duodenum was perfused through a fifth catheter whose openings were $4 \mathrm{~cm}$ beyond the distal pressure orifice.

In subjects who had fasted overnight, the recording unit was passed into the second or third portion of the duodenum under direct fluoroscopic visualization. All measurements were made with the patient in the right lateral decubitus position. After stable readings were observed, the recording assembly was slowly withdrawn at $0.5-\mathrm{cm}$ intervals from duodenum to stomach, recording at each interval for $1 \mathrm{~min}$. Basal records were obtained in all subjects. After the basal pull-through, the assembly was again passed into the duodenum and the pyloric response to the intravenous administration of various gastrointestinal hormones was investigated. At least $1 \mathrm{~h}$ was allowed between testing of different hormones. Individual pull-through measurements were recorded during administration of gastrin $\mathrm{I}$ at $1 \mu \mathrm{g} /$ $\mathrm{kg}-\mathrm{h}$ and $2 \mu \mathrm{g} / \mathrm{kg}-\mathrm{h}$, secretin at $1.0 \mathrm{U} / \mathrm{kg}-\mathrm{h}$ (clinical units), cholecystokinin at $2.0 \mathrm{U} / \mathrm{kg}$-h (Ivy dog units) (GIH Research (nit, Stockholm, Sweden) and the combination of secretin and cholecystokinin at the above doses, in each subject. Each pull-through was performed $10 \mathrm{~min}$ after hormonal administration had begun. Individual pull-through measurements were also performed during the duodenal infusion of $0.1 \mathrm{~N} \mathrm{HCl}$ at $7.6 \mathrm{cc} / \mathrm{min}(48 \mathrm{meq} / \mathrm{h})$ alone, and with simultaneous intravenous administration of gastrin I at $1 \mu \mathrm{g} / \mathrm{kg}-\mathrm{h}$ and $2 \mu \mathrm{g} / \mathrm{kg}-\mathrm{h}$. Each subject received all intravenous test substances in random order. Each endogenous and exogenous pyloric response was compared to a basal level obtained between stimuli. The Student's $t$ test was utilized in the statistical analysis of the data (20).

\section{RESULTS}

In vitro studics. All data was computed on the basis of the peak response to each hormone or hormone combination. Quantification of the peak response at the length of optimal tension development, Lo normalized the responses of muscle with dissimilar length-tension properties (17). At Lo, each muscle was capable of generating its peak active tension to a given stimulus. Thus, Lo provided a constant reference for the study of muscle from different portions of the gastrointestinal tract and for the study of muscle from the same portion on different days. The maximum absolute responses of pyloric circular muscle to each hormone administered are listed in Table I. All subsequent dose-response curves are constructed using the maximum absolute response to the single hormone that yielded the greatest active tension

TABLE I

Comparison of Maximum Absolute Responses of Pyloric Circular Muscle

$\begin{array}{lr}\text { Peak active tension to secretin, } g & 4.6 \pm 1.0 \\ \text { Peak active tension to cholecystokinin, } g & 7.9 \pm 1.5 \\ \text { Peak active tension to gastrin I, } g & -0.7 \pm 0.2 \\ \text { Peak active tension to octapeptide of } & 10.8 \pm 1.1 \\ \quad \text { cholecystokinin, } g & \end{array}$

Each value represents the mean $\pm \mathrm{SE}$ of 12 separate determinations. 


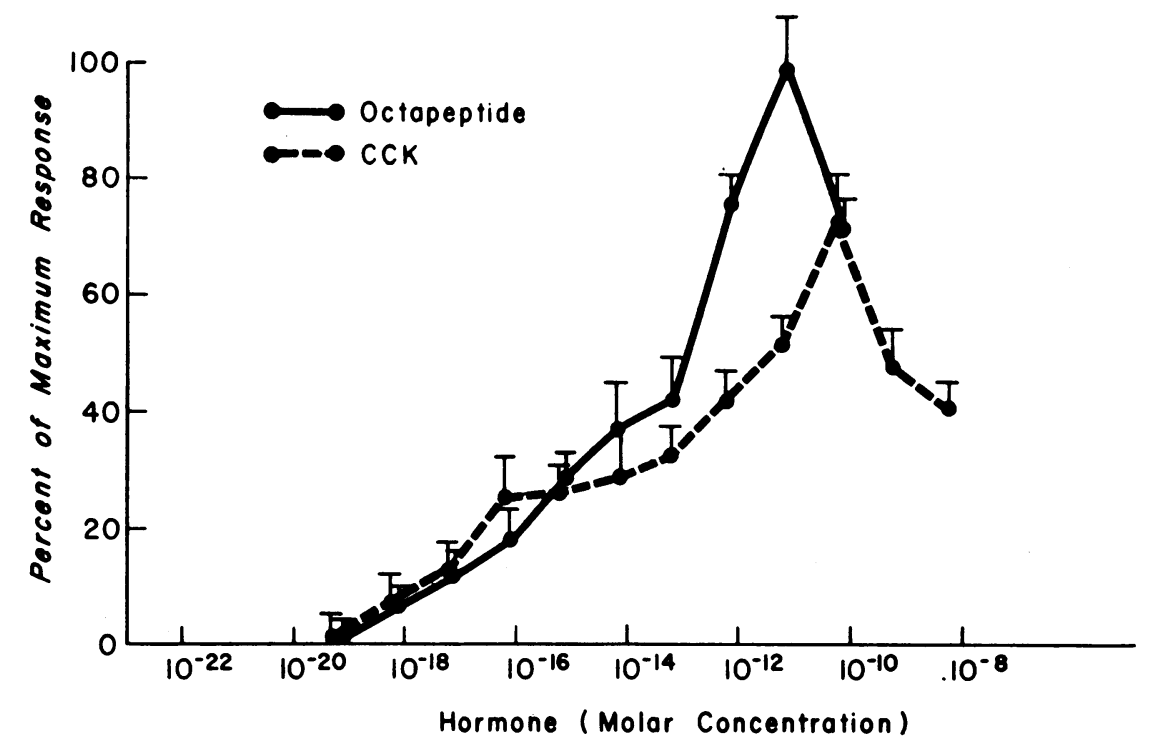

FIGURE 3 Octapeptide of cholecystokinin and cholecystokinin dose-response curves at Lo, for pyloric circular muscle. Active tension is expressed as a percent of maximum response to the octapeptide of cholecystokinin. Synthetic octapeptide gave a significantly greater response at molar concentrations of cholecystokinin, $8.7 \times 10^{-13}$ and $8.7 \times 10^{-12}(P<0.001)$.

within the respective figure. All statistical comparisons are based upon absolute values for data obtained on the same muscle strips.

In Fig. 1 the cholecystokinin log dose-response curves are shown for circular muscle obtained from the duodenum, pylorus, and antrum. The responses of the muscle from each region are expressed as a percent of the maximum response of the pylorus, the muscle that developed the greatest active tension. The threshold and the peak responses for the pyloric circular muscle occurred at lower doses than for either the adjacent antrum or duodenum. The pyloric muscle showed a prominent diminution in response to cholecystokinin at doses beyond the peak value of $7.5 \times 10^{-11} \mathrm{M}$. Next the dose-

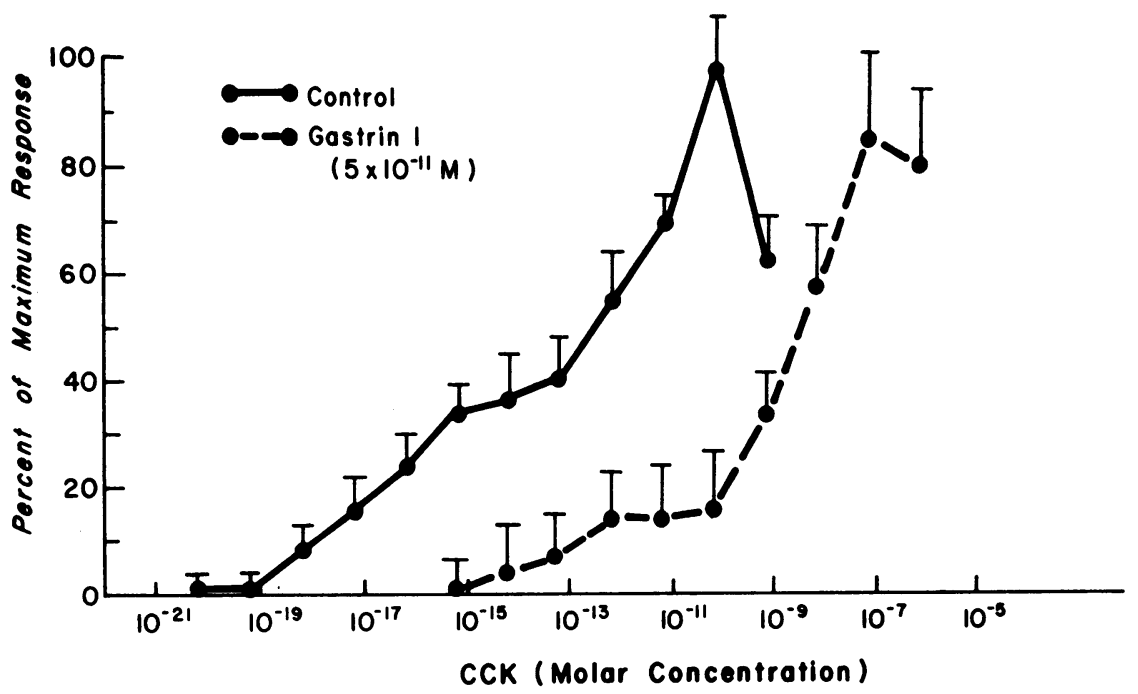

FIGURE 4 Dose-response curves, at Lo, for cholecystokinin (CCK) alone and in the presence of $5 \times 10^{-11} \mathrm{M}$ gastrin I, on pyloric muscle. Active tension is expressed as a percent of maximum response to cholecystokinin when given alone. Each point represents mean+SE for 12 separate experiments. In the presence of gastrin I, the threshold dose of cholecystokinin was increased and the maximum response to cholecystokinin was achieved. The slope of the steep linear portion of the cholecystokinin curve $(y=-19.2 x+3.07, r=0.98)$ did not differ from the comparable slope $(y=-20.8 x+2.75, r=0.99)$ in the presence of gastrin $(P>0.05)$. 


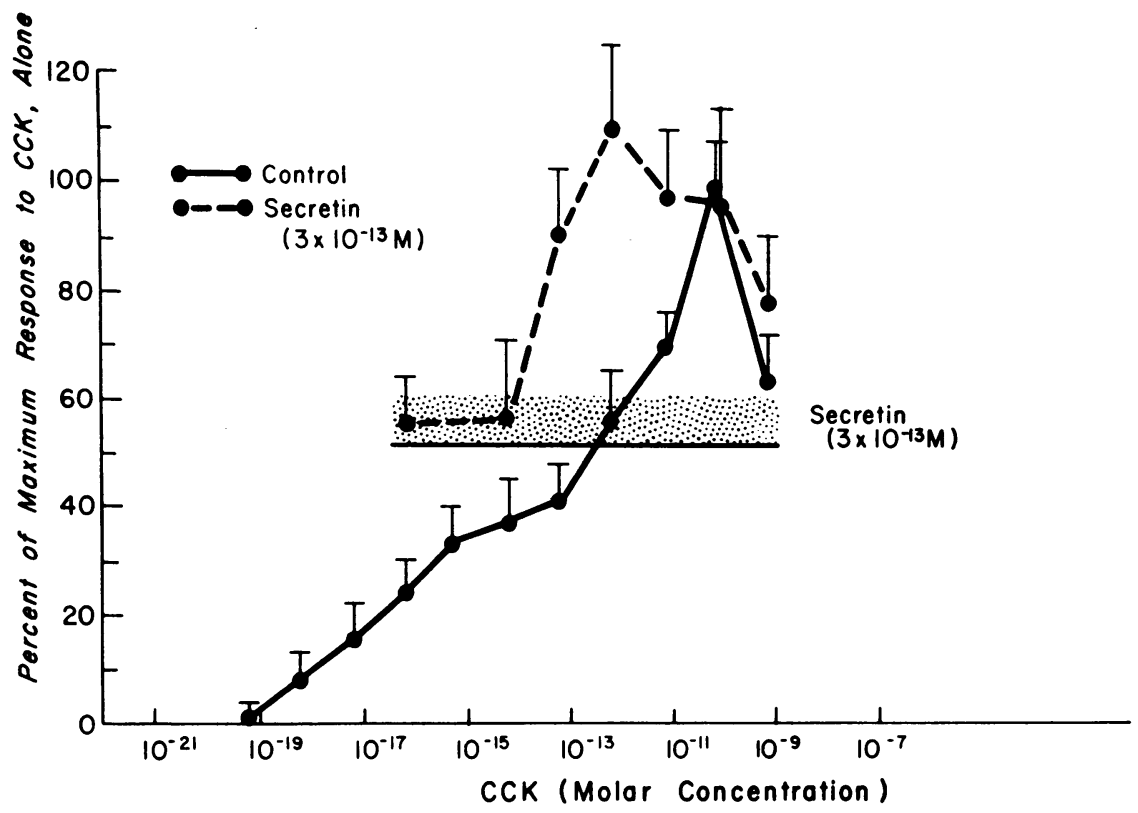

Figure 5 Dose-response curves, at Lo, for cholecystokinin (CCK) alone, and in the presence of $3 \times 10^{-13} \mathrm{M}$ secretin, on pyloric muscle. Active tension is expressed as a percent of maximal response to cholecystokinin alone. Each point represents mean+SE for 12 separate experiments. The horizontal line represents the maximal tension to secretin alone. In the presence of secretin, the maximal response to cholecystokinin occurred at a lower concentration but the maximal response was not altered $(P>0.05)$.

response curve of pyloric muscle to cholecystokinin was compared to the dose-response curves of the other hormones.

In Fig. 2 the log dose-response curves of pyloric muscle are compared for secretin, gastrin I, and cholecystokinin. The response of the pyloric muscle is expressed as a percent of the maximal active tension to cholecystokinin. Both cholecystokinin and secretin contracted pyloric muscle while gastrin I gave no response. Although cholecystokinin gave a response at the lowest threshold dose and developed the greatest active tension, secretin developed its maximum response at a lower molar concentration than cholecystokinin.

To evaluate the pyloric muscle response to a synthetic purified form of cholecystokinin, a dose-response curve was constructed for the synthetic terminal octapeptide of cholecystokinin. In Fig. 3 the dose-response curves for both cholecystokinin and the octapeptide are compared. The data is expressed as a percent of the maximal active tension to the octapeptide. The octapeptide gave a significantly greater response at a lower concentration than the whole molecule of cholecystokinin $(P<0.001)$.

The interaction of different hormone combinations was studied next. In Fig. 4 the log dose-response curves for pyloric circular muscle are shown for cholecystokinin, alone, and for the combination of cholecystokinin with gastrin I. In the presence of gastrin $\mathrm{I}\left(5 \times 10^{-11} \mathrm{M}\right)$, the entire dose-response curve to cholecystokinin was shifted to higher concentrations. The threshold dose was greater and in the presence of gastrin I, the maximum response to cholecystokinin was still attained at higher concentrations. No significant difference was found between the slopes of the steep linear phases of each dose-response curve.

In Fig. 5 the dose-response curves are shown for cholecystokinin alone, and cholecystokinin in the presence of secretin $\left(3 \times 10^{-13} \mathrm{M}\right)$. This is the concentration of secretin that produced the maximum active tension on pyloric muscle. The data is expressed as a percent of the maximal active tension to cholecystokinin, alone. The horizontal line indicates the maximal tension to secretin, alone. In the presence of secretin, the maximal response to cholecystokinin was not significantly increased. However, the maximal response occurred at a lower concentration. Similar findings in the magnitude of the maximal response to cholecystokinin were observed when secretin was added $5 \mathrm{~min}$ before the cholecystokinin; the additive effects of secretin were not seen at lower cholecystokinin concentrations.

In viz'o studies. The hormonal responses observed in muscle strips in vitro, were next evaluated in human subjects under basal conditions and during the intravenous infusion of each gastrointestinal hormone or hormone combination. The recording assembly was slowly withdrawn at $0.5-\mathrm{cm}$ intervals from duodenum to 


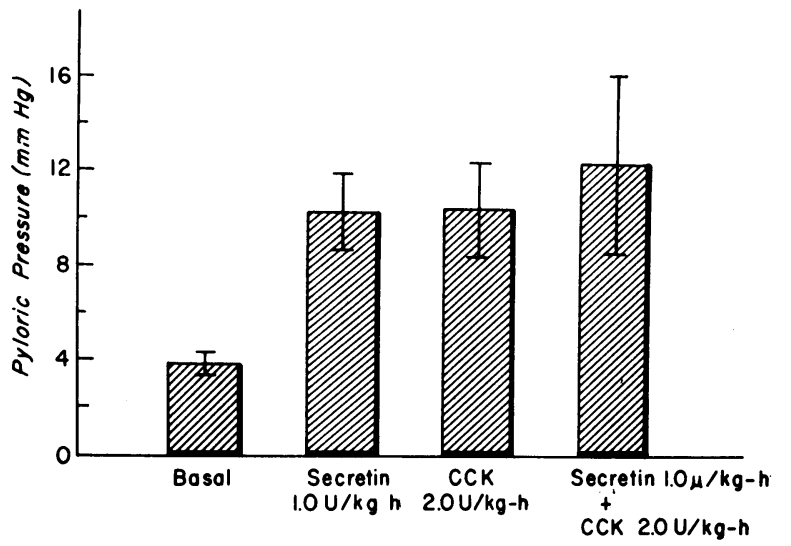

Figure 6 Human pyloric response to the intravenous administration of secretin and cholecystokinin (CCK), alone and in combination. Data is expressed in millimeters $\mathrm{Hg}$ above intraabdominal pressure. Each bar represents mean $\pm \mathrm{SE}$ of 10 experiments. The human pyloric responses to secretin, cholecystokinin and the combination were significant $(P<0.01)$. The response to the hormone combination was not greater than the individual hormone maximal responses $(P>0.05)$.

stomach in each subject. The pylorus was identified as previously described, by the change in skin to mucosa $\mathrm{PD}$ at the gastroduodenal junction $(1,21,22)$.

The pyloric pressure responses to the intravenous administration of secretin and cholecystokinin alone and in combination in 10 subjects are shown in Fig. 6. All pressures are expressed using intragastric pressure as a zero reference. The basal pyloric pressure was $3.8 \pm 0.3$ $\mathrm{mm} \mathrm{Hg}$ (mean $+\mathrm{SE}$ ). In response to secretin (1 $\mathrm{U} / \mathrm{kg}-\mathrm{h}$ ) pyloric pressure increased significantly above basal level to $10.3 \pm 1.6 \mathrm{~mm} \mathrm{Hg}(P<0.01)$. Cholecystokinin $(2 \mathrm{U} / \mathrm{kg}-\mathrm{h})$ increased pyloric pressure to a maximal value of $10.4 \pm 1.9 \mathrm{~mm} \mathrm{Hg}(P<0.01)$. Secretin infusion at doses of $0.25,0.50$, and $2.0 \mathrm{U} / \mathrm{kg}-\mathrm{h}$ and cholecystokinin infusion at doses of $0.5,1.0$, and 3.0 $\mathrm{U} / \mathrm{kg}$-h gave lower responses than to those doses cited above. The combination of secretin and cholecystokinin at maximal doses produced the greatest level of pyloric pressure, $12.5 \pm 3.7 \mathrm{~mm} \mathrm{Hg}$. However, this response to the hormone combination did not significantly differ from the response to either hormone administered separately. The length of the pyloric high pressure zone was approximately $1.5 \mathrm{~cm}$ and did not change with hormonal stimulation. The pylorus was closely associated with an abrupt mean PD change of minus $33.4 \pm 2.6 \mathrm{mV}$ as the tube was withdrawn from duodenum to stomach. This, too, was not altered by gastrointestinal hormones.

The effect of gastrin I on pyloric pressure was next evaluated as shown in Fig. 7. During the intravenous infusion of gastrin I ( $1 \mu \mathrm{g} / \mathrm{kg}-\mathrm{h}$ and $2 \mu \mathrm{g} / \mathrm{kg}-\mathrm{h})$ pyloric pressure did not significantly change from basal level. To determine whether gastrin I could affect the pyloric response to endogenous hormonal stimulation, the py- loric pressure was quantified during duodenal acidification $(0.1 \mathrm{~N} \mathrm{HCl}, 7.6 \mathrm{cc} / \mathrm{min}, 48 \mathrm{meq} / \mathrm{h})$ alone, and during acidification with simultaneous gastrin $\mathrm{I}$ administration. In response to duodenal acidification alone pyloric pressure increased from its basal level of $3.8 \pm$ $0.3 \mathrm{~mm} \mathrm{Hg}$ to $16.1 \pm 3.6 \mathrm{~mm} \mathrm{Hg}(P<0.001)$. During gastrin I administration at $1 \mu \mathrm{g} / \mathrm{kg}-\mathrm{h}$ and simultaneous duodenal acidification, pyloric pressure increased to $10.8 \pm 2.6 \mathrm{~mm} \mathrm{Hg}$. At $2 \mu \mathrm{g} / \mathrm{kg}-\mathrm{h}$ of gastrin I, the pyloric pressure during duodenal acidification was only $4.7 \pm 1.8$ $\mathrm{mm} \mathrm{Hg}$. Only the diminution in response to $2 \mu \mathrm{g} / \mathrm{kg}-\mathrm{h}$ of gastrin was statistically significant when compared to the control response to duodenal acidification $(P<$ $0.001)$.

\section{DISCUSSION}

Recently, it has been observed that individual gastrointestinal sphincters may have different responses to the gastrointestinal hormones, both in vitro and in vivo. The lower esophageal sphincter contracts in response to gastrin (12-14) whereas both the ileocecal (15) and choledochal sphincters (16) are inhibited. Contrary to previous studies, the pylorus has now been shown to have properties similar to other gastrointestinal sphincters (1). In the resting state it is characterized by a zone of high pressure. This high pressure zone relaxes preceding antral peristalsis. Furthermore, in man, pyloric pressure increases in response to intraduodenal stimuli such as $0.1 \mathrm{~N} \mathrm{HCl}$, olive oil, and amino acids which are known to release secertin and cholecystokinin. In dogs pyloric contraction has also been reported in response to the administration of the octapeptide of cholecystokinin (3). The purpose of this study was to investigate the responses of pyloric circular muscle to the gastrointestinal hormones given singularly and in combination, in vitro, and to correlate these observations with the behavior of the human pyloric sphincter, in vivo. Our results indicated that pyloric circular muscle responds specifically to each gastrointestinal hormone tested. Secretin and cholecystokinin are agonists contracting the muscle, in vitro, and increasing pyloric pressure, in vivo. Gastrin $I$ is an antagonist inhibiting the effects of the other hormones.

Initial studies indicated that pyloric circular muscle responded at lower concentrations of cholecystokinin and developed a greater maximal active tension than muscle from either the adjacent antrum or duodenum. Secretin also contracted the pyloric muscle but the maximal active tension was less than that attained with cholecystokinin. The interaction of secretin and cholecystokinin showed an additive effect at submaximal concentrations but at the maximal concentration of both hormones, the response did not significantly exceed the response to cholecystokinin, alone. Thus, potentiation was not demonstrated by this criterion $(23,24)$. The 
more potent response to the octapeptide of cholecystokinin as compared to the whole molecule was consistent with other effects of this residue (25) and suggested that contaminants present in the GIH Research Unit preparation of cholecystokinin were not solely responsible for the observed response (26-28).

These observations on muscle preparations correlated with the findings in man. The pyloric pressure increased in response to either cholecystokinin or secretin and the maximal response to each hormone was similar. The response to their combined administration did not differ significantly from the maximal response to each hormone given separately. Again, potentiation of the maximal response was not demonstrated. The increase in pyloric pressure during duodenal acidification was significantly greater than the response to hormonal administration. This observation may be explained by either the presence of impurities in the hormone preparation (26-28) or the existence of other hormonal and neural mechanisms which may be involved in the acidification response. Further studies are required to resolve this point.

The effect of gastrin I on pyloric muscle differed from that of either cholecystokinin or secretin. Gastrin I had no independent effect on pyloric circular muscle, but yet could antagonize the effect of cholecystokinin. In the presence of gastrin I, the cholecystokinin dose-response curve was shifted to higher doses. The threshold dose was increased and the steep phase of linear response remained parallel to that of the dose-response curve to cholecystokinin, alone. The maximum response was attained at higher doses of cholecystokinin. These features characterize competitive inhibition (29). We have shown previously that gastrin I antagonized the effect of secretin on pyloric muscle, but here the kinetics were noncompetitive $(18,29)$. These features of gastrin I antagonism for secretin and cholecystokinin on pyloric muscle are consistent with the gastrointestinal hormone receptor hypothesis proposed by Grossman (30).

Observations on human pyloric function, in vivo, indicated that while gastrin I did not increase pyloric pressure significantly at any dose, it acted as an antagonist to the endogenous hormonal stimulation of the pylorus produced by perfusion of the duodenum with $0.1 \mathrm{~N}$ $\mathrm{HCl}$. This observation was consistent with the antagonism of gastrin I for secretin and cholecystokinin on the pyloric muscle since duodenal acidification releases both hormones $(4,5)$.

The relevance of these observations to the function of the pylorus must be interpreted cautiously. We have previously suggested that an important function of the pylorus is the prevention of duodeno-gastric reflux of bile because duodenal acidification in normals markedly reduced the amount of reflux of duodenal contents into the stomach (1). The most likely mechanism by which

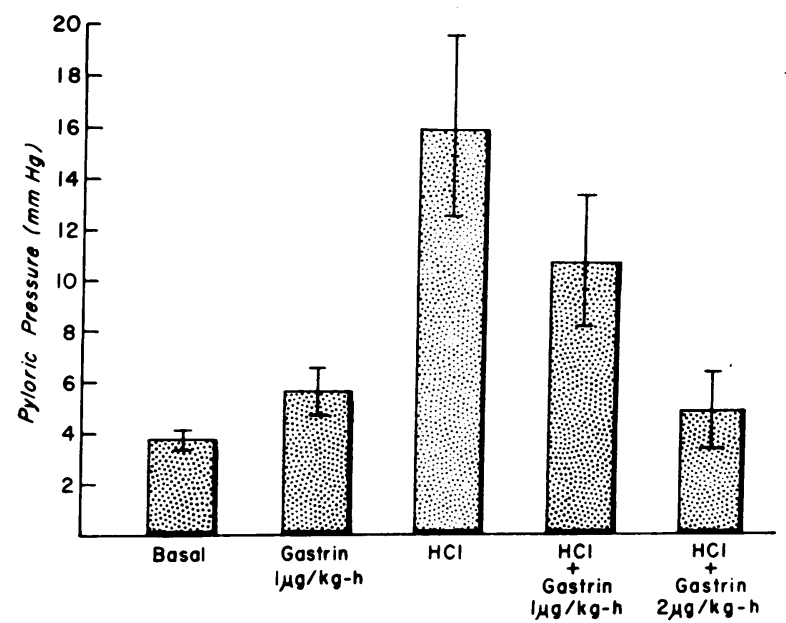

FigURe 7 Human pyloric response to duodenal acidification alone and during the intravenous administration of graded doses of gastrin I. Data is expressed in millimeters $\mathrm{Hg}$ above intraabdominal pressure. Each bar represents the mean $\pm \mathrm{SE}$ of 10 experiments. Gastrin I, administered alone, did not significantly alter pyloric pressure $(P>0.05)$. Duodenal acidification, alone significantly increased pyloric pressure to $16.1 \pm 3.6 \mathrm{~mm} \mathrm{Hg}(P<0.001)$. During gastrin I administration at $1 \mu \mathrm{g} / \mathrm{kg}-\mathrm{h}$ and $2 \mu \mathrm{g} / \mathrm{kg}$-h there was a graded decrease in the response to duodenal acidification.

the pylorus serves this protective function would be the release of the duodenal hormones, secretin and cholecystokinin, in response to acidification. This would be analogous to the role of gastrin in maintaining lower esophageal sphincter competence (12-14). However, other hormonal or neural pathways can not be excluded.

Another possible function of the pylorus may be the control of gastric emptying. Secretin and cholecystokinin are thought to inhibit gastric emptying. Intraduodenal amino acids, known to release only cholecystokinin (7), and intraduodenal $\mathrm{HCl}$ known to release secretin (4), both delay gastric emptying (31). Exogenous secretin (32) and cholecystokinin (33) also delay gastric emptying. The role of the pylorus in gastric emptying is difficult to resolve because secretin and cholecystokinin not only increase pyloric tone but they also inhibit antral motility $(19,34)$. Therefore, the effect of these hormones upon emptying may be through either increased pyloric resistance or decreased antral propulsive force. Gastrin's effect on gastric emptying is even more complex. Since gastrin is known to increase antral motor activity (35) and inhibit pyloric contraction, we would predict an acceleration of gastric emptying. Quite the contrary, a diminution of gastric emptying has been reported $(36,37)$. However, this effect could be explained by a decrease in antral propulsive force rather than by an alteration of pyloric tone. Certainly, the physiologic role of the pylorus in the prevention of duodenogastric reflux and in the regulation of gastric emptying requires further investigation. 


\section{ACKNOWLEDGMENTS}

The authors wish to thank Miss Aileen Lahti and Mrs. Fe Green for their expert technical assistance.

This work was supported by Training Grant TR-15A from the Veterans Administration, Clinical Research Center Grant S-MOIRR-40 from the Division of Research Facilities and Resources, and Research Grant 1 RO1 AM 1628001 from the National Institutes of Health. Dr. Cohen was supported, in part, by Clinical investigator funds from the Veterans Administration and by Research Career Development Award 1 K-4 AM 70, 576-01 from the National Institutes of Health.

\section{REFERENCES}

1. Fisher, R. S., and S. Cohen. 1972. The physiologic characteristics of the human pyloric sphincter. Gastroenterology. $64: 67$.

2. Brink, B. M., J. F. Schlegel, and C. F. Code. 1965. The pressure profile of the gastroduodenal junctional zone in dogs. Gut. $6: 163$.

3. Isenberg, J. I., and A. Csendes. 1972. Effect of octapeptide of cholecystokinin on canine pylorus pressure. Am. J. Physiol. 222 : 428.

4. Nakajima, S., and D. F. Magee. 1970. Influence of duodenal acidification on acid and pepsin secretion of the stomach in dogs. Am. J. Physiol. 218: 545.

5. Barbezat, G. O., and M. I. Grossman. 1971. Cholecystokinin released by duodenal acidification. Gastroenterology. 60 : 761. (Abstr.)

6. Johnson, L. R., and M. I. Grossman. 1969. Effects of fat, secretin and cholecystokinin on histamine-stimulated gastric secretion. Am. J. Physiol. 216: 1176.

7. Go, V. L. W., A. F. Hofmann, and W. A. J. Summerskill. 1970. Pancreozymin bioassay in man based on pancreatic enzyme secretion: potency of specific amino acids and other digestive products. J. Clin. Invest. 49: 1558.

8. Young, J. D., L. Lazarus, and D. J. Chisholm. 1969. Radioimmunoassay of pancreozymin-cholecystokinin in human serum. J. Nucl. Med. 10: 743 .

9. Young, J. D., L. Lazarus, and D. J. Chisholm. 1968. Secretin and pancreozymin-cholecystokinin after glucose. Lancet. 2 : 914.

10. Chisholm, D. J., J. D. Young, and L. Lazarus. 1969. The gastrointestinal stimulus to insulin release. I. Secretin. J. Clin. Invest. 48: 1453.

11. Kraegen, E. W., D. J. Chisholm, J. D. Young, and L. Lazarus. 1970. The gastrointestinal stimulus to insulin release. II. A dual action of secretin. J. Clin. Invest. $49: 524$.

12. Castell, D. O., and L. D. Harris. 1970. Hormonal control of gastroesophageal sphincter strength. N. Engl. J. Med. 282: 886

13. Giles, G. R., M. D. Mason, C. Humphries, and C. G. Clark. 1969. Action of gastrin on the lower oesophageal sphincter in man. Gut. 10: 730 .

14. Cohen, S., and W. Lipshutz. 1971. Hormonal regulation of human lower esophageal sphincter competence: interaction of gastrin and secretin. J. Clin. Invest. 50: 449.

15. Castell, D. O., S. Cohen, and L. D. Harris. 1970. Response of human ileocecal sphincter to gastrin. Am. J. Physiol. 219: 712 .
16. Lin, T. M. 1971. Hepatic, cholecystokinetic and choledochal action of cholecystokinin, secretin, caerulein and gastrin-like peptides. Proc. Int. Cong. Physiol. Sci. 9: Abstr. 1877.

17. Lipshutz, W. H., and S. Cohen. 1971. Physiologic determinants of lower esophageal sphincter function. Gastroenterology. $61: 16$.

18. Lipshutz, W. H., and S. Cohen. 1972. Interaction of gastrin I and secretin on gastrointestinal circular muscle. Am. J. Physiol. 222: 775.

19. Vagne, M., G. F. Stening, F. P. Brooks, and M. I. Grossman. 1968. Synthetic secretin: comparison with natural secretin for potency and spectrum of physiological actions. Gastroenterology. 55: 260.

20. Snedecor, G. W., and W. G. Cochran. 1967. Statistical Methods. Iowa State University Press, Ames.

21. Andersson, S., and M. I. Grossman. 1965. Profile of $\mathrm{pH}$, pressure, and potential difference at gastroduodenal junction in man. Gastroenterology. 49: 364.

22. Blackwood, W. D. 1969. Pylorus identification. Gastroenterology $57: 163$.

23. Henriksen, F. W. 1969. Concept of potentiation. Gastroenterology. $57: 617$.

24. Meyer, J. H., L. J. Spinzola, and M. I. Grossman. 1971. Endogenous cholecystokinin potentiates exogenous secretin on pancreas of dog. Am. J. Physiol. 221: 742.

25. Rubin, B., A. M. Engel, A. M. Drungis, M. Dzelzalns, E. O. Grigas, M. H. Waugh, and Yiacas. 1969. Cholecystokinin-like activities in guinea pigs and in dogs of the C-terminal octapeptide (SQ 19, 844) of cholecystokinin. J. Pharm. Sci. 58: 955.

26. Brown, J. C., R. A. Pederson, E. Jorpes, and V. Mutt. 1970. Preparation of highly active enterogastrone. $J$. Physiol. (Lond.). 209: 54.

27. Lucien, H. W., Z. Itoh, and A. V. Sholly. 1970. Inhibitory effects of purified enterogastrone, secretin, and cholecystokinin on histamine stimulated gastric acid secretion. Gastroenterology. 59 : 707.

28. Magee, D. F., and B. Dutt. 1972. Effect of pure and commercial cholecystokinin and an inhibitory polypeptide on gastric secretion. Am. J. Physiol. 222: 73.

29. Ariens, E. J., editor. 1964. Molecular Pharmacology. Academic Press, Inc., New York. 1.

30. Grossman, M. I. 1970. Hypothesis: gastrin, cholecystokinin and secretin act on one receptor. Lancet. 1: 1088.

31. Thomas, J. E. 1957. Mechanics and regulation of gastric emptying. Physiol. Rev. $37: 453$.

32. Vagne, M., and C. Andre. 1971. The effect of secretin on gastric emptying in man. Gastroenterology. 60: 421.

33. Chey, W. Y., S. Hitenant, J. Hendricks, and S. H. Lorber. 1968. Effect of intestinal hormones on human gastric function. Gastroenterology. 54: 1225. (Abstr.)

34. Johnson, L. P., J. C. Brown, and D. F. Magee. 1966. Effects of secretin and cholecystokinin-pancreozynim extracts on gastric motility in man. Gut. 7: 52.

35. Misiewicz, J. J., D. J. Holdstock, and S. L. Waller. 1967. Motor responses of the human alimentary tract to near-maximal infusions of pentagastrin. Gut. 8: 463.

36. Hunt, J. N., and N. Ramsbottom. 1967. Effect of gastrin II on gastric emptying and secretion during a test meal. Br. Med. J. $4: 386$.

37. Dozois, R. R., and K. A. Kelly. 1971. Effect of a gastrin pentapeptide on canine gastric emptying of liquids. Am. J. Physiol. 221: 113. 